In the interim, the importance of this branch of industry has increased all over the world and in addition there has been an unprecedented industrial development in Germany brought about by the planned transformation of the national economic system. It is expected, therefore, that the Exhibition next July will offer unusual opportunities and that it will attract a large number of expert visitors from all parts. The Achema Bureau is located in Berlin, W.35, Potsdamerstrasse 103a.

\section{Proton-Neutron Exchange Interaction}

REFERring to his letter in Nature of June 12 (p. 1021), Mr. H. J. Bhabha states that he omitted to insert the following at the beginning of the final paragraph : "The above experiment may be done with cosmic rays, but it must be emphasized that we do not know that the penetratmg group consists of protons, even though we know it cannot consist of electrons obeying the theory."

\section{The Night Sky in July}

THE duration of darkness is too short this month to scan a number of interesting objects. Mars, Jupiter and Saturn are to be seen, followed by Venus, which is a bright morning star. On July 17 at $21^{\mathrm{h}}$ U.T. $\left(=22^{\mathrm{h}}\right.$ summer time), Mars is in conjunction with the moon, and an occultation is visible from Great Britain. The disappearance of Mars behind the moon as seen from Greenwich takes place at $21^{\mathrm{h}} 17 \cdot 7^{\mathrm{m}}$ and the reappearance at $22^{\mathrm{h}} 19 \cdot 8^{\mathrm{m}}$. Jupiter is in opposition on July 15 ; its equatorial diameter is $47 \frac{1}{2}$ " and its polar diameter $3^{\prime \prime}$ less, the oblateness of the disk being apparent in quite a small telescope. On July $22^{\mathrm{d}} 21^{\mathrm{h}}$, Jupiter is in conjunction with the moon. The configurations of the four inner satellites of the planet are given for $23^{\mathrm{h}} 45^{\mathrm{m}}$ in the Nautical Almanac of 1937, p. 625. Saturn with its ring system is, of course, nearly always an attractive object for observation with a refractor of 3 inches aperture or larger. The planet is stationary amongst the stars on July 18. The moon is new on July 8 at $4 \cdot 2^{\mathrm{h}}$ and full on July 23 at $12 \cdot 8^{\mathrm{h}}$. The occultation with Mars when the moon is $9 \cdot 7^{\mathrm{d}}$ old has been mentioned above. On July 31 a conjunction of Mercury with the bright star Regulus may be noted. The planet is only $0 \cdot 4^{\circ}$ north of the star (geocentric positions). About midnight ( $23^{\mathrm{h}}$ U.T.) in the middle of the month, a bright and interesting stretch of the Milky Way is passing the meridian of London. The Constellations Scorpio, Sagittarius, Aquila, Cygnus (south of the zenith) and Cassiopeia, Perseus and Auriga (to the north) mark its span. In latitudes somewhat farther south than that of London, the galactic star clouds in Scorpio and Sagittarius are an unforgettable sight which may be guessed at on clear moonless nights in Great Britain. Though less spectacular, the low eastern sky at midnight contains the constellation Andromeda, and by locating the great nebula, which can be done with the unaided eye, we are seeing out to the depths of space beyond our galactic system. A number of meteor radiants are active during July, among which may be noted the $\alpha \beta$ Perseids with radiant at R.A. $3^{\mathrm{h}} 12^{\mathrm{m}}$ : Dec. $43^{\circ} \mathrm{N}$.; $\gamma$ Draconids (radiant, R.A. $17^{\mathrm{h}} 56^{\mathrm{m}}:$ Dec. $48^{\circ}$ N.) and the $\delta$ Aquarids (radiant R.A. $22^{\mathrm{h}} 36^{\mathrm{m}}$ : Dec. $\left.11^{\circ} \mathrm{S}.\right)$. Some swift meteors may be seen from the radiant at R.A. $21^{\mathrm{h}} 0^{\mathrm{m}}$; Dec. $48^{\circ} \mathrm{N}$.- the $\alpha$ Cygnids.

\section{Announcements}

H.M. THE KING has nominated Sir Arthur MacNalty to be for five years a member of the General Council of Medical Education in the United Kingdom in succession to Sir Henry Dale.

THE following awards from the Lady Tata Memorial Fund for research in blood diseases, with special reference to leukæmia, have recently been made: Grants for research expenses, Dr. Julius EngelbrethHolm (Copenhagen), Prof. Karl Jarmai (Budapest), Prof. James MeIntosh (London), Prof. Charles Oberling (Paris), Prof. Eugene Opie and Dr. Jacob Furth (New York), Dr. Georg Weitzmann (Leipzig) and Dr. Lucy Wills (London); Scholarships, Dr. Jørgen Bichel (Aarhus, Denmark) and Dr. Edoardo Storti (Pavia, Italy).

A Conference on the "Challenge to Democracy" will be held at Ashridge College, Berkhamsted, by the Association for Education in Citizenship, on July 8-14. Further information can be obtained from the Secretary, Association for Education in Citizenship, 10 Victoria Street, S.W.1.

As earthquake of moderate intensity was recorded at Kew Observatory on June 21. The first impulses were registered at $15 \mathrm{hr} .26 \mathrm{~min} .2 \mathrm{sec}$. G.M.T. The records indicate that the shock was located about 6,000 miles away, probably in Peru.

Prof. Hugo Spatz has been appointed director of the Kaiser Wilhelm Institute for Cerebral Investigations.

AN international congress of public health consisting of ten sections will be held in Paris on July 1-10. Further information can be obtained from the Secrétariat Général, Laboratorie d'Hygiene, Faculte de Médecine, rue de l'Ecole de Médecine, Paris, $5^{\mathrm{e}}$

The Belgian Government has decided to organize a campaign of health with the trtle of the National Crusade of Health under the direction of the Red Cross.

Dr. Max Wien, professor of physics at Jena, and Prof Oskar Seyffert at Dresden, have been awarded the Goethe Medal for art and science by the German Chancellor.

THE first World Congress on the Voice, organized by Euphonia, will be held at La Maison de la Chimie, Paris, on September 19-28. Further information can be obtained from Dr. Wicart, 92 Avenue de Wagram, Paris. 